\title{
The impact of health literacy in the care of surgical patients: a qualitative systematic review
}

\author{
Gildasio S. De Oliveira Jr. ${ }^{1 *}$, Robert J. McCarthy ${ }^{1}$, Michael S. Wolf ${ }^{2}$ and Jane Holl ${ }^{3}$
}

\begin{abstract}
Background: Inadequate health literacy affects more than 90 million Americans and it has been associated with adverse outcomes in the medicine field including increased hospitalization rates and greater mortality. Since surgical patients are often required to make complex decisions and adhere to complex instructions, health literacy may have a profound impact in the surgical practice. The main objective of the current study was to systematically evaluate the role of health literacy in surgical patients.

Methods: A systematic search was performed to identify studies that evaluated the role of health literacy in the perioperative setting following the PRISMA guidelines. Only studies that examined health literacy using a validated instrument in the perioperative setting were included.

Results: Ten studies including data on 1147 patients were included. The median (IQR) number of patients in the included studies was 101 (30 to 152). The majority of studies used the Short Test of Functional Literacy in adults (STOFHLA) to evaluate patients' health literacy. Five studies evaluated the patients preoperatively, four studies evaluated patients in the postoperative period and in one study the time of evaluation in relation to the surgical procedure was not defined. The lowest prevalence of inadequate health literacy was detected in kidney transplant patients, 6 out of $124(5 \%)$, while the highest prevalence of inadequate health literacy was detected in orthopedic patients having total joint replacement, 86 out of 126 (60\%). Inadequate health literacy in the preoperative period was associated with poor medical information comprehension and it may adversely affect adherence to preoperative medications and even modulate surgical disparities. Inadequate health literacy in the postoperative period was associated with poor comprehension of discharge instructions and worse kidney function in transplant recipients.
\end{abstract}

Conclusions: Health literacy seems to have a very significant impact in the care of surgical patients. More studies to establish the impact of poor health literacy on perioperative outcomes are needed.

\section{Background}

Health literacy is the ability to comprehend and use health information in order to make appropriate health decisions [1]. It has been estimated that over 90 million Americans have inadequate health literacy [2], that makes them unable to understand basic instructions and make appropriate health related decisions [3]. In non-surgical patients, several large studies have demonstrated an association between poor health literacy and negative patient outcomes such as increased hospitalizations and greater mortality $[4,5]$. In addition, poor health literacy has been estimated to cause

\footnotetext{
* Correspondence: g-jr@northwestern.edu

'Department of Anesthesiology, Feinberg School of Medicine, Northwestern University, 241 East Huron St, F5-704 Chicago, IL, USA

Full list of author information is available at the end of the article
}

an economic burden to the health care system of approximately $\$ 75$ billion per year in the US alone [6].

Health literacy is likely to have a very important role in the care of perioperative patients. In addition of an understanding of the health information they are provided, numeracy skills are required to make decisions regarding elective surgical procedures. Frequently, patients are required to follow complex preoperative and postoperative instructions and lack of adherence to those instructions can result in negative outcomes or cancellation of surgical procedures $[7,8]$. Despite the established role of health literacy and outcomes in non-surgical patients, the role of health literacy in surgical patients is currently not well defined.

\section{() Biomed Central}


The main objective of the current systematic review was to evaluate health literacy in surgical patients. We also sought to examine the current reported prevalence of patients with inadequate health literacy in the same population.

\section{Methods}

We performed a quantitative systematic review following the guidelines of the Preferred Reporting Items for Systematic Reviews and Meta-Analyses statement (PRISMA) [9]. The current manuscript is a review article and does not require IRB approval.

\section{Systematic search}

Published reports of studies evaluating health literacy in the perioperative setting were searched using the National Library of Medicine's Pubmed database, the Cochrane Database of Systematic Reviews and Google Scholar inclusive to November $15^{\text {th }}, 2013$. Free text and MeSH terms 'literacy', 'health', 'surgery', 'perioperative', 'preoperative', 'postoperative' and 'operation' were used individually and in pairwise combinations. No language restriction was used. An attempt to identify additional studies not found by the primary search methods was made by reviewing the reference lists from identified studies. No search was performed for unpublished studies. This initial search yielded 291 manuscripts.

\section{Selection of included studies}

The study's inclusion and exclusion criteria were determined before the systematic search. Two authors (GDO and RJM) independently evaluated the abstract and results of the 291 articles obtained by the initial search. Articles that were clearly not relevant based on our inclusion and exclusion criteria were excluded at this phase. Disagreements on inclusion of the articles were resolved by discussion among the evaluators. If an agreement could not be reached, the dispute was resolved with the help of a third investigator. The third investigator was blinded regarding evaluation of the first two authors.

\section{Inclusion and exclusion criteria}

We included published manuscripts that evaluated health literacy in perioperative patients. Included studies had to report on health literacy using a validated instrument. Inclusion of studies was not limited by the timing of healthy literacy evaluation in relation to the surgical procedure (preoperative or postoperative). Studies that examined topics related to health literacy but did not include reports on patients were excluded. Excluded also were studies that performed simple readability tests of patient education materials. No minimum sample size was required for inclusion in the systematic review.

\section{Validity scoring}

The Newcastle-Ottawa scale was used to assess the methodological quality of cohort and case-control studies [10]. The Newcastle-Ottawa scale contains eight items that are divided in three sections: selection (four items), comparability (one item) and exposure (three items). A star is given to each category that presents a high-quality choice of individual study. For randomized trials a modified Jadad five point quality scale was used to assess study quality. The scale evaluates the study for the following: randomization, double blind evaluation, concealment of study group to evaluator, valid randomization method and completeness of data at follow-up [11]. Two authors (GSD and RJM) independently read the included reports and assessed their methodological validity. Discrepancies in rating of the trials were resolved by discussion among the evaluators. If an agreement could not be reached, the dispute was resolved with the help of another investigator. Studies were not excluded or weighted in the analysis based on quality assessment scores.

\section{Data extraction}

Two authors (GDO and RJM) independently evaluated the full manuscripts of all included studies and performed data extraction using a data collection form specifically developed for this review.

Discrepancies were resolved by discussion between the two investigators (GDO and RJM). If an agreement could not be reached between the two investigators, the decision was made by another investigator. Data extracted from studies included the health literacy instrument used, type of surgical specialty, time in relation to surgical procedure (preoperative, intraoperative or postoperative), type of intervention, evaluated outcomes, study design, sample size, number of subjects with inadequate literacy, and follow-up period.

Data were initially extracted from tables or text. For data not available in tables, the data was abstracted from available figures. Dichotomous data on the presence or absence of adverse effects was extracted and converted to incidence, while continuous data was recorded using mean and standard deviation.

\section{Meta-analyses}

Quantitative analysis was not performed due to the large heterogeneity of study designs, interventions and measured outcomes.

\section{Results}

Of the 291 initially evaluated abstracts, 32 studies were initially selected. Twenty-two studies were subsequently excluded: ten studies did not evaluate patients [12-21], nine studies did not measure health literacy or did not use a validated instrument [22-30], and three did not evaluate patients in the perioperative setting [31-33] 
(Fig. 1). The characteristics of included studies are listed in Table 1. The studies evaluated included data from 1147 subjects in a variety of surgical procedures and were published between 2004 and 2013 [34-43]. The median (IQR) number of patients in the included studies was 101 (30 to 152). The majority of studies used the Short Test of Functional Literacy in adults (STOFHLA) to evaluate patients' health literacy. Five studies evaluated the patients preoperatively [34-36, 40, 43], four studies evaluated patients in the postoperative period $[37,38,41,44]$, and in one study the time of evaluation in relation to the surgical procedure was not defined [39]. The lowest prevalence of inadequate health literacy was detected in kidney transplant patients, 6 out of 124 (5\%) [41], while the highest prevalence of inadequate health literacy was detected in orthopedic patients having total knee or total joint replacement, 86 out of 126 (60\%).

One study developed and validated a rapid estimated of adult literacy specific for vascular surgery patients

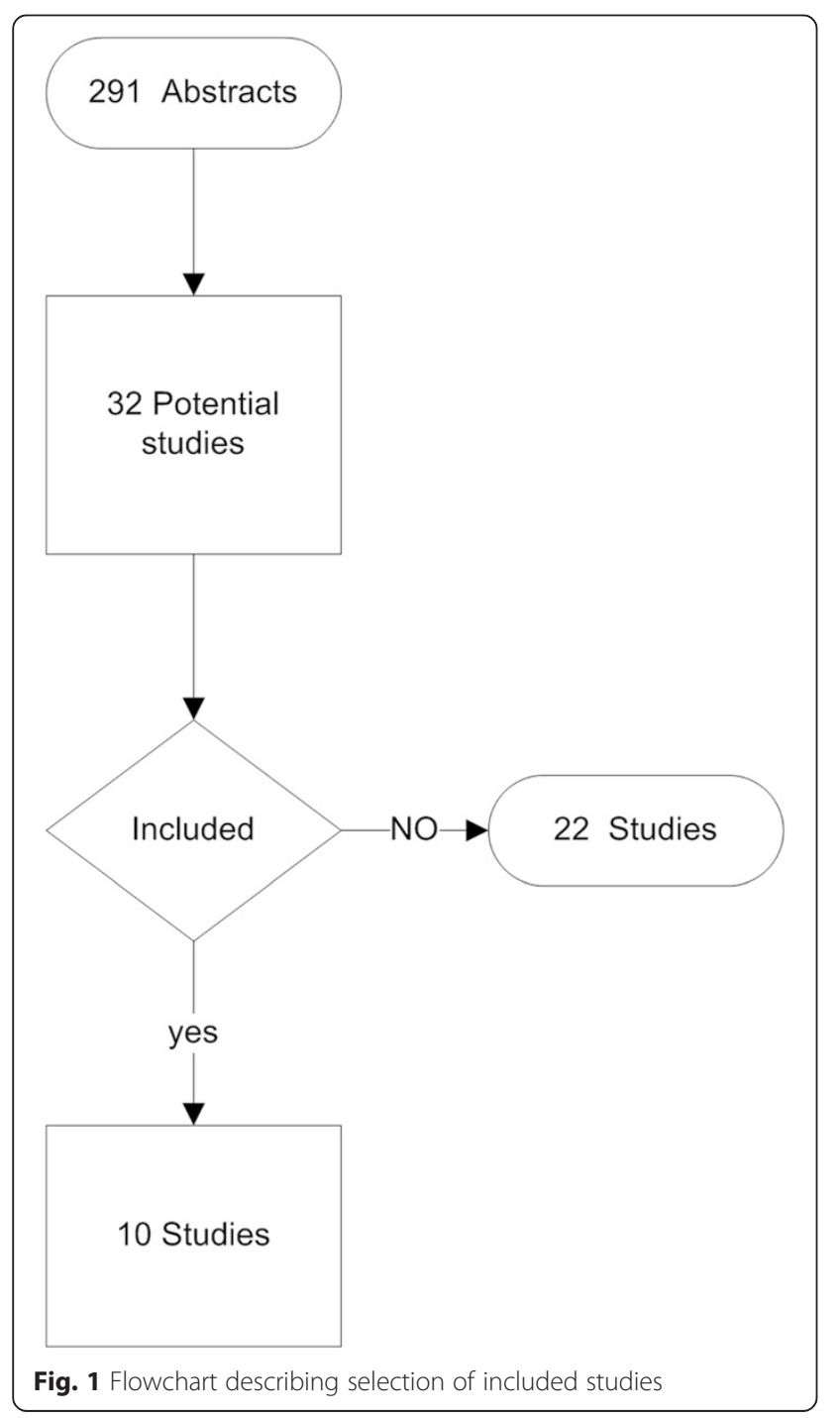

(Real_VS) [39]. The instrument had high internal consistency (Cronbachs $\alpha=0.98$ ) and high correlation with REALM scores (Spearman's rank correlation $=0.91$ ).

\section{Health literacy in the preoperative period}

Five studies evaluated patients during the preoperative period [34-36, 40, 43]. Two studies (one a crosssectional design and one case - control design) limited to evaluate the association of poor health literacy with information comprehension and information satisfaction [34, 35]. The study of Chu et al. [34] demonstrated using a validated questionnaire that patient comprehension of perioperative information was dependent on health literacy even after adjusting for provider's empathy. In contrast, the study of Otal et al. [35] did not find an association between healthy literacy and patient satisfaction with perioperative information.

Two prospective cohort studies examined the association of health literacy and important perioperative outcomes [40, 43]. Chew et al. [42] evaluated the association between health literacy and adherence to preoperative medications in 332 ambulatory surgical patients. Despite observing a greater non-adherence to preoperative medications among patients with inadequate health literacy, the study was underpowered to detect a statistically significant difference, odds ratio ( $95 \%$ CI) of 1.9 (0.8 to 4.8). Grubbs et al. [40] conducted a prospective cohort study to examine an association between health literacy and access to kidney transplant list among patients with chronic kidney failure. The authors found that subjects with inadequate health literacy were less likely to be referred to a transplant list, hazard ratio $(95 \% \mathrm{CI})$ of 0.22 (0.08 to 0.6 ), after adjusting for confounding factors such as age, gender, race and income.

Only one randomized trial evaluated the effect of low literacy consent on patient's comprehension of the consent process in patients undergoing laparoscopic tubal ligation [36]. Women who were randomized to a low literacy consent form understood the consent process better than the women who were randomized to the standard consent form. However, the authors did not use a validated instrument to measure patient comprehension.

\section{Health literacy in the postoperative period}

Four studies investigated the role of health literacy in the postoperative care of surgical patients [37, 38, 41, 44]. Three studies had a cross sectional design and one was based on discussions of focus groups.

One study evaluated the prevalence of inadequate health literacy in patients who underwent total laryngectomy [38]. The estimation was limited by the extremely small sample size $(n=8)$ and by a large proportion of patients lost to follow up. 
Table 1 Summary of studies included in analysis

\begin{tabular}{|c|c|c|c|c|c|c|c|c|}
\hline Authors & $\begin{array}{l}\text { Year of } \\
\text { study }\end{array}$ & $\begin{array}{l}\text { Surgical } \\
\text { specialty }\end{array}$ & $\begin{array}{l}\text { Number inadequate } \\
\text { health literacy/total } \\
\text { subjects }\end{array}$ & $\begin{array}{l}\text { Health } \\
\text { literacy } \\
\text { instrument }\end{array}$ & Study design & Intervention & Outcome & $\begin{array}{l}\text { Newcastle-Ottawa } \\
\text { scale }^{a} \text { or modified } \\
\text { Jadad score }\end{array}$ \\
\hline Chu et al. [34] & 2013 & Orthopedic & $86 / 144$ & REALM & Case-control & None & $\begin{array}{l}\text { Medical information } \\
\text { comprehension }\end{array}$ & $4^{\mathrm{a}}$ \\
\hline Otal et al. [35] & 2012 & Pediatrics & $30 / 79$ & $\begin{array}{l}\text { Newest } \\
\text { Vital Sign }\end{array}$ & Cross-sectional & None & $\begin{array}{l}\text { Satisfaction with } \\
\text { information }\end{array}$ & $3^{a}$ \\
\hline Zite et al. [36] & 2011 & Gynecology & $102 / 201$ & $\begin{array}{l}\text { Chew's } \\
\text { screening } \\
\text { items }\end{array}$ & $\begin{array}{l}\text { Randomized } \\
\text { controlled trial }\end{array}$ & $\begin{array}{l}\text { Low literacy } \\
\text { consent form }\end{array}$ & $\begin{array}{l}\text { Consent form } \\
\text { comprehension }\end{array}$ & $3^{b}$ \\
\hline Choi et al. [37] & 2011 & Orthopedics & $15 / 15$ & S-TOHFLA & Focus groups & $\begin{array}{l}\text { Pictograph } \\
\text { based } \\
\text { discharge } \\
\text { instructions }\end{array}$ & None & - \\
\hline Beitler et al. [38] & 2010 & $\begin{array}{l}\text { Ear Nose } \\
\text { and Throat }\end{array}$ & $3 / 8$ & S-TOHFLA & Cross-sectional & None & None & $3^{a}$ \\
\hline Wallace et al. [39] & 2009 & Vascular & $70 / 152$ & REALM & Cross-sectional & None & None & $3^{\mathrm{a}}$ \\
\hline Grubbs et al. [40] & 2009 & Transplant & $14 / 62$ & TOHFLA & Cohort & None & $\begin{array}{l}\text { Access to kidney } \\
\text { transplant }\end{array}$ & $5^{a}$ \\
\hline Gordon et al. [41] & 2009 & Transplant & $6 / 124$ & $\begin{array}{l}\text { S-TOHFLA/ } \\
\text { REALM-T }\end{array}$ & Cross-sectional & None & Kidney function & $5^{8}$ \\
\hline Chew et al. [42] & 2004 & $\begin{array}{l}\text { All ambulatory } \\
\text { surgeries }\end{array}$ & $40 / 332$ & S-TOHFLA & Cohort & None & $\begin{array}{l}\text { Adherence to } \\
\text { preoperative } \\
\text { instructions }\end{array}$ & $5^{a}$ \\
\hline Conlin et al. [43] & 2002 & Heart Surgery & $6 / 30$ & REALM & Cross-sectional & None & $\begin{array}{l}\text { Discharge } \\
\text { Instruction } \\
\text { comprehension }\end{array}$ & $3^{a}$ \\
\hline
\end{tabular}

anewcastle-Ottawa scale

bJadad score

One cross-sectional study evaluated the role of health literacy on patients ability to understand discharge instructions after cardiac surgery [44]. The authors detected a strong correlation between healthy literacy but not educational level with patients' ability to comprehend discharge instructions (Pearson's coefficient $=0.67$ ). Another cross-sectional study evaluated the association between health literacy and creatinine levels in patients after kidney transplant [41]. The authors found a small but independent association between lower levels of health literacy and greater levels of creatinine $(\beta=-0.3$, $95 \%$ CI -0.05 to $-0.00 ; P=0.03$ ).

One author performed a focus group study to evaluate the effect of pictograph -based discharge instructions in patients that underwent hip replacement surgery [37]. Although the author concluded that pictograph based discharge instructions was an effective strategy to present discharge instructions for patients with inadequate health literacy, no formal analyses were presented by the author.

\section{Discussion}

The most important finding of the current systematic review was the paucity of studies examining health literacy in the perioperative setting. In addition, current studies in surgical settings had very limited sample sizes especially when compared to studies in the medical setting $[44,45]$. Several investigations were excluded because they did not even use a validated instrument to measure health literacy but often use educational level as a surrogate. Since healthy literacy has been associated with poor patient outcomes (including death) in the medical setting $[5,46]$, our systematic review establishes the extreme need for additional studies evaluating the role of health literacy in the perioperative setting.

Most of the included studies were observational and only one study examined a low-literacy patient communication intervention using a randomized controlled design [36]. The study was limited because the primary outcome (patient comprehension) was evaluated using a non-validated questionnaire. Doak et al. has provided a strategy through the Suitability of Assessment Material (SAM) to offer objective medical information in an appropriate manner to patients, especially those with limited health literacy [47]. In contrast, decision aids in the surgical setting have failed to adjust for different levels of healthy literacy among patients [48].

Health literacy is considered a major driving factor in explaining disparities in health care [49]. Multiple studies have evaluated disparities in surgical care but not the role of health literacy [50-52]. We were able 
to identify only one study that demonstrated a very strong association between poor health literacy and lack of patients' enrollment on kidney transplant lists [40]. It is possible that health literacy may explain part of the currently described disparity in surgical services $[53,54]$. Future studies attempting to explain disparities in surgical care should incorporate measurements of health literacy in their evaluation.

It was interesting to note that the reported rates of inadequate health literacy varied substantially among different surgical procedures. Poor health literacy had low prevalence in recipients of kidney transplants $(4 \%)$ but it had high prevalence among orthopedic patients having hip and knee replacements [34, 41]. Since poor health literacy has been repeatedly associated with advancing age $[55,56]$, it is possible that different age characteristics has contributed to the differences in inadequate health literacy among the evaluated surgical groups. Nevertheless, due to the relatively small sample sizes of included investigations, larger comprehensive studies are needed to establish which surgical specialties are most vulnerable to have patients with poor health literacy.

Currently, approximately $70 \%$ of surgical procedures are performed in the ambulatory setting [57]. The ambulatory setting may be particular challenge for low literacy elderly patients that need hospital support but are sent home, irrespective of health literacy skills. In addition, discharge instructions are often given after surgery where cognitive function may be decreased due to anesthesia and analgesic medications $[58,59]$. A recent study has demonstrated that age is an independent risk factor for the development of venous thrombosis after ambulatory surgery [60]. It remains to be determined if adequate health literacy skills are associated with a safer discharge of elderly ambulatory surgical patients.

Our systematic review should only be interpreted in the context of its limitations. Due to the low number of interventions and a variety of outcomes examined, we were unable to perform a quantitative analysis. Consequently, we were not able to examine the data for publication bias. We cannot, therefore, exclude the possibility of negative studies that were "file-drawer" and could have refuted the influence of inadequate health literacy on surgical outcomes. We were also not able to detect which levels of health literacy are critical for optimal outcomes in perioperative patients. The time constraints commonly seen in the surgical setting may require greater levels of health literacy from surgical patients than what has been established for optimal outcomes in the non-surgical specialties.

\section{Conclusions}

In summary, we evaluated the role of health literacy for patient care in the perioperative setting. The evaluated studies suggest that poor health literacy may be associated with inadequate comprehension of the surgical procedure and discharge instructions. In addition health literacy may be implicated with poor adherence to preoperative instruction which may jeopardize patient safety. Lastly, surgical disparities may also be, in part, explained by inadequate literacy. The lack of large studies confirming those preliminary findings and the lack of interventions to address limited perioperative health literacy call for an extreme need to develop a research agenda in order to minimize the effects of poor health literacy in the care of surgical patients.

\section{Competing interests}

The authors declare that they have no competing interests.

\section{Authors' contributions}

GDO participated in the study design, conduct of the study, data analysis and manuscript preparation; RJM participated in the conduct of the study and manuscript preparation; MSW participated in the study design and manuscript preparation; JLH participated in the study design and manuscript preparation. All authors read and approved the final manuscript.

\section{Author details}

'Department of Anesthesiology, Feinberg School of Medicine, Northwestern University, 241 East Huron St, F5-704 Chicago, IL, USA. '2Department of Medicine, Feinberg School of Medicine, Northwestern University, Chicago, USA. ${ }^{3}$ Center for Health Care studies, Northwestern University, Chicago, USA.

Received: 22 August 2014 Accepted: 9 July 2015

Published online: 17 July 2015

\section{References}

1. Oldach BR, Katz ML. Health literacy and cancer screening: A systematic review. Patient Educ Couns. 2013 Oct 14. [Epub ahead of print]

2. Wolf MS, Davis TC, Shrank W, Rapp DN, Bass PF, Connor UM, et al. To err is human: patient misinterpretations of prescription drug label instructions. Patient Educ Couns. 2007;67:293-300.

3. Smith SG, Curtis LM, Wardle J, von Wagner C, Wolf MS. Skill set or mind set? Associations between health literacy, patient activation and health. PLoS One. 2013;8:e74373.

4. Mitchell SE, Sadikova E, Jack BW, Paasche-Orlow MK. Health literacy and 30-day postdischarge hospital utilization. J Health Commun. 2012;17:325-38.

5. Baker DW, Wolf MS, Feinglass J, Thompson JA, Gazmararian JA, Huang J. Health literacy and mortality among elderly persons. Arch Intern Med. 2007;167:1503-9.

6. Berkman ND, Sheridan SL, Donahue KE, Halpern DJ, Crotty K. Low health literacy and health outcomes: an updated systematic review. Ann Intern Med. 2011;155:97-107.

7. Hovlid E, von Plessen C, Haug K, Aslaksen AB, Bukve O. Patient experiences with interventions to reduce surgery cancellations: a qualitative study. BMC Surg. 2013;13:30

8. Toussi R, Fujioka K, Coleman KJ. Pre- and postsurgery behavioral compliance, patient health, and postbariatric surgical weight loss. Obesity (Silver Spring). 2009;17:996-1002.

9. Liberati A, Altman DG, Tetzlaff J, Mulrow C, Gøtzsche PC, loannidis JP, et al. The PRISMA statement for reporting systematic reviews and meta-analyses of studies that evaluate health care interventions: Explanation and elaboration. J Clin Epidemiol. 2009;62:e1-34.

10. Stang A. Critical evaluation of the Newcastle-Ottawa scale for the assessment of the quality of nonrandomized studies in meta-analyses. Eur J Epidemiol. 2010;25:603-5.

11. Jadad AR, Moore RA, Carroll D, Jenkinson C, Reynolds DJ, Gavaghan DJ, et al. Assessing the quality of reports of randomized clinical trials: is blinding necessary? Control Clin Trials. 1996;17:1-12.

12. Misra P, Agarwal N, Kasabwala K, Hansberry DR, Setzen M, Eloy JA. Readability analysis of healthcare-oriented education resources from the 
American Academy of Facial Plastic and Reconstructive Surgery. Laryngoscope. 2013;123:90-6.

13. Colaco M, Svider PF, Agarwal N, Eloy JA, Jackson IM. Readability assessment of online urology patient education materials. J Urol. 2013;189:1048-52.

14. Shukla P, Sanghvi SP, Lelkes VM, Kumar A, Contractor S. Readability assessment of internet-based patient education materials related to uterine artery embolization. J Vasc Interv Radiol. 2013;24:469-74.

15. Fabricant PD, Dy CJ, Patel RM, Blanco JS, Doyle SM. Internet search term affects the quality and accuracy of online information about developmental hip dysplasia. J Pediatr Orthop. 2013;33:361-5.

16. Jayaratne YS, Anderson NK, Zwahlen RA. Readability of websites containing information on dental implants. Clin Oral Implants Res. 2013 Oct 22. [Epub ahead of print]

17. Misra P, Kasabwala K, Agarwal N, Eloy JA, Liu JK. Readability analysis of internet-based patient information regarding skull base tumors. J Neurooncol. 2012;109:573-80.

18. Sanghvi S, Cherla DV, Shukla PA, Eloy JA. Readability assessment of internet-based patient education materials related to facial fractures. Laryngoscope. 2012;122:1943-8.

19. Dy CJ, Taylor SA, Patel RM, Kitay A, Roberts TR, Daluiski A. The effect of search term on the quality and accuracy of online information regarding distal radius fractures. J Hand Surg [Am]. 2012;37:1881-7.

20. Abed H, Rogers R, Helitzer D, Warner TD. Informed consent in gynecologic surgery. Am J Obstet Gynecol. 2007;197:674.e1-5.

21. Anscher MS, Gold DT. Literacy and laryngectomy: how should one treat head and neck cancer in patients who cannot read or write? South Med J. 1991;84:209-13.

22. Atchison KA, Black EE, Leathers R, Belin TR, Abrego M, Gironda MW, et al. A qualitative report of patient problems and postoperative instructions. J Oral Maxillofac Surg. 2005;63:449-56.

23. Kumar S, Mohanraj R, Rose A, Paul MJ, Thomas G. How 'informed' is informed consent? Findings from a study in South India. Indian J Med Ethics. 2012;9:180-6.

24. Hoppe IC, Ahuja NK, Ingargiola MJ, Granick MS. A survey of patient comprehension of readily accessible online educational material regarding plastic surgery procedures. Aesthet Surg J. 2013;33:436-42.

25. Cegala DJ, Chisolm DJ, Nwomeh BC. A communication skills intervention for parents of pediatric surgery patients. Patient Educ Couns. 2013;93:34-9.

26. Chaibou MS, Sanoussi S, Sani R, Toudou NA, Daddy H, Madougou M, et al. Management of postoperative pain: experience of the Niamey National Hospital. Niger J Pain Res. 2012;5:591-5.

27. Jibaja-Weiss ML, Volk RJ, Granchi TS, Neff NE, Robinson EK, Spann SJ, et al. Entertainment education for breast cancer surgery decisions: a randomized trial among patients with low health literacy. Patient Educ Couns. 2011:84:41-8.

28. Miller MJ, Abrams MA, Earles B, Phillips K, McCleeary EM. Improving patient-provider communication for patients having surgery: patient perceptions of a revised health literacy-based consent process. J Patient Saf. 2011;7:30-8.

29. Kadakia RJ, Tsahakis JM, Issar NM, Archer KR, Jahangir AA, Sethi MK, et al. Promoting health communication between the community-dwelling well-elderly and pharmacists: the Ask Me 3 program. J Am Pharm Assoc (2003). 2008:48:784-92

30. Hawley ST, Janz NK, Hamilton A, Griggs JJ, Alderman AK, Mujahid M, et al. Latina patient perspectives about informed treatment decision making for breast cancer. Patient Educ Couns. 2008;73:363-70.

31. Okamoto M, Kyutoku Y, Sawada M, Clowney L, Watanabe E, Dan I, et al. Health numeracy in Japan: measures of basic numeracy account for framing bias in a highly numerate population. BMC Med Inform Decis Mak. 2012;12:104

32. Escobedo W, Weismuller P. Assessing health literacy in renal failure and kidney transplant patients. Prog Transplant. 2013;23(1):47-54. doi:10.7182/pit2013473.

33. Anger JT, Lee UJ, Mittal BM, Pollard ME, Tarnay CM, Maliski S, et al. Health literacy and disease understanding among aging women with pelvic floor disorders. Female Pelvic Med Reconstr Surg. 2012;18:340-3.

34. Chu Cl, Tseng CC. A survey of how patient-perceived empathy affects the relationship between health literacy and the understanding of information by orthopedic patients? BMC Public Health. 2013;13:155.
35. Otal D, Wizowski L, Pemberton J, Nagel K, Fitzgerald P, Walton JM. Parent health literacy and satisfaction with plain language education materials in a pediatric surgery outpatient clinic: a pilot study. J Pediatr Surg. 2012:47:964-9.

36. Zite NB, Wallace LS. Use of a low-literacy informed consent form to improve women's understanding of tubal sterilization: a randomized controlled trial. Obstet Gynecol. 2011;117:1160-6.

37. Choi J. Older adults' perceptions of pictograph-based discharge instructions after hip replacement surgery. J Gerontol Nurs. 2013;39:48-54.

38. Beitler JJ, Chen AY, Jacobson K, Owens A, Edwards M, Johnstone PA. Health literacy and health care in an inner-city, total laryngectomy population. Am J Otolaryngol. 2010;31:29-31.

39. Wallace LS, Ergen WF, Cassada DC, Freeman MB, Grandas OH, Stevens SL, et al. Development and validation of the Rapid Estimate of Adult Literacy in Vascular Surgery (REAL_VS). Ann Vasc Surg. 2009;23:446-52.

40. Grubbs V, Gregorich SE, Perez-Stable EJ, Hsu CY. Health literacy and access to kidney transplantation. Clin J Am Soc Nephrol. 2009;4:195-200

41. Gordon EJ, Wolf MS. Health literacy skills of kidney transplant recipients. Prog Transplant. 2009;19:25-34.

42. Chew LD, Bradley KA, Flum DR, Cornia PB, Koepsell TD. The impact of low health literacy on surgical practice. Am J Surg. 2004;188:250-3.

43. Conlin KK, Schumann L. Literacy in the health care system: a study on open heart surgery patients. J Am Acad Nurse Pract. 2002;14:38-42.

44. Federman $A D$, Wolf MS, Sofianou A, O'Conor R, Martynenko M, Halm EA, Leventhal $H$, Wisnivesky JP. Asthma outcomes are poor among older adults with low health literacy. J Asthma. 2013 Nov 14. [Epub ahead of print]

45. Waite KR, Federman AD, McCarthy DM, Sudore R, Curtis LM, Baker DW, et al. Literacy and race as risk factors for low rates of advance directives in older adults. J Am Geriatr Soc. 2013;61:403-6.

46. Wu JR, Holmes GM, DeWalt DA, Macabasco-O'Connell A, Bibbins-Domingo $K$, Ruo B, et al. Low literacy is associated with increased risk of hospitalization and death among individuals with heart failure. J Gen Intern Med. 2013;28:1174-80

47. Doak CC, Doak LG, Root JH. Teaching patients with low literacy skills. 2nd ed. Philadelphia, PA: JB Lippincott; 1996

48. Knops AM, Legemate DA, Goossens A, Bossuyt PM, Ubbink DT. Decision aids for patients facing a surgical treatment decision: a systematic review and meta-analysis. Ann Surg. 2013;257:860-6.

49. Sentell T, Braun KL. Low health literacy, limited English proficiency, and health status in Asians, Latinos, and other racial/ethnic groups in California. J Health Commun. 2012;17:82-99.

50. Moo-Young TA, Panergo J, Wang CE, Patel S, Duh HY, Winchester DJ, et al. Variations in clinicopathologic characteristics of thyroid cancer among racial ethnic groups: analysis of a large public city hospital and the SEER database. Am J Surg. 2013:206:632-40.

51. Howell EA, Egorova N, Hayes MP, Wisnivesky J, Franco R, Bickell N. Racial disparities in the treatment of advanced epithelial ovarian cancer. Obstet Gynecol. 2013;122:1025-32

52. Munene G, Parker RD, Shaheen AA, Myers RP, Quan ML, Ball CG, et al. Disparities in the surgical treatment of colorectal liver metastases. J Natl Med Assoc. 2013;105:128-37.

53. Mohandas R, Casey MJ, Cook RL, Lamb KE, Wen X, Segal MS. Racial and socioeconomic disparities in the allocation of expanded criteria donor kidneys. Clin J Am Soc Nephrol. 2013;8:2158-64.

54. Thammana RV, Knechtle SJ, Romero R, Heffron TG, Daniels CT, Patzer RE. Racial and socioeconomic disparities in pediatric and young adult liver transplant outcomes. Liver Transpl. 2013 t 17. [Epub ahead of print]

55. Kobayashi LC, Wardle J, von Wagner C. Limited health literacy is a barrier to colorectal cancer screening in England: Evidence from the English Longitudinal Study of Ageing. Prev Med. 2013 Nov 25 [Epub ahead of print]

56. Kaup AR, Simonsick EM, Harris TB, Satterfield S, Metti AL, Ayonayon HN, Rubin SM, Yaffe K. Older Adults With Limited Literacy Are at Increased Risk for Likely Dementia. J Gerontol A Biol Sci Med Sci. 2013 Oct 24. [Epub ahead of print]

57. Joshi GP, Ahmad S, Riad W, Eckert S, Chung F. Selection of obese patients undergoing ambulatory surgery: a systematic review of the literature. Anesth Analg. 2013;117:1082-91. 
58. Steinmetz J, Siersma V, Kessing LV, Rasmussen LS, ISPOCD Group. Is postoperative cognitive dysfunction a risk factor for dementia? A cohort follow-up study. Br J Anaesth. 2013;110:92-7.

59. Radtke FM, Franck M, Lendner J, Krüger S, Wernecke KD, Spies CD. Monitoring depth of anaesthesia in a randomized trial decreases the rate of postoperative delirium but not postoperative cognitive dysfunction. $\mathrm{Br} \mathrm{J}$ Anaesth. 2013;110:98-105.

60. Pannucci CJ, Shanks A, Moote MJ, Bahl V, Cederna PS, Naughton NN, et al. Identifying patients at high risk for venous thromboembolism requiring treatment after outpatient surgery. Ann Surg. 2012;255:1093-9.

\section{Submit your next manuscript to BioMed Central} and take full advantage of:

- Convenient online submission

- Thorough peer review

- No space constraints or color figure charges

- Immediate publication on acceptance

- Inclusion in PubMed, CAS, Scopus and Google Scholar

- Research which is freely available for redistribution 